comers who may find it formidable - this is supposedly an entry-level book. However, it belies its title.

There are several defects. The authors fail to anticipate the reader's likely difficulties in grasping the cock-eyed nomenclatures with which the subject has grown up. The book is also full of mistakes. Again, Fig. 1.1 sets the tone. In it, Thy-1 is incorrectly shown as having a transmembrane hydrophobic peptide; a depiction of the correct lipid anchor doesn't arrive until page 298, though even here Fig. 12.10 dithers. Out of 16 figures in Chapter 7 that have been taken from the original literature, seven have mistakes, four of which are so serious as to make the diagrams incomprehensible. Errors in the text include malapropisms (for example, 'syngeneic' for 'syntenic', page 266) and contradictions with the figures. No reader of a textbook should have to double-guess its authors to such an extent.

Finally, the book is out of date. Its structure rests mainly on a historical narrative, which frequently doesn't connect with the present. The introduction hints that the pregnancy through which its authors laboured was like that of a marsupial suffering delayed implantation, and it shows. The references in Chapters 5 and 6 ("Classical Genetics of Immunoglobulins" and "Antibody Diversity") stop at 1981; those in Chapters 9 and 10 , on the genetics of the MHC, include only one later than 1983. So there are gaping structural omissions.

Is there really even a separate discipline of immunogenetics that requires an undergraduate textbook? This one, with its excursions towards the scattered destinations of immune proteins, genes, cells and diseases, raises unfortunate doubts whether there is. The publishers ought in this case to reassess the balance between their own reputation and what they owe to their authors.

Simon Hunt is a Lecturer in the Dunn School of Pathology, University of Oxford, OX1 3RE, UK, and a Fellow of Keble College.

\section{Ordered order}

\section{lan Tattersall}

Primate Adaptation and Evolution. By John G. Fleagle. Academic:1988. Pp. 486. \$39.95, £28.

Human Blology: An Introduction to Human Evolution, Varlation, Growth, and Adaptability, 3rd edn. By G. A. Harrison, J. M. Tanner, D. R. Pilbeam and P. T. Baker. Oxford University Press: 1988. Pp.568. HbK £40, \$70; pbk $£ 20, \$ 35$.

EVEN a superficial comparison of John Fleagle's new introduction to the primates with its predecessor, Le Gros Clark's The Antecedents of Man, dramatically illustrates how much primatology has changed over the three decades separating the two books. The comparative anatomical foundation on which Antecedents was based has expanded enormously and has been given an important functional component; a vast quantity of behavioural and ecological information has been amassed; and our understanding of primate systematics has been revolutionized, both practically and theoretically.

Each of these developments is reflected in Fleagle's book, which is a tour de force as well as a tour d'horizon of the primate order. The preliminaries are dealt with briskly in three short chapters, "Adaptation, Evolution, and Systematics", "The Primate Body" and "Primate Life". Most of the rest of the book is composed of accounts of the main groups of primates, the living followed by the extinct.

For the living forms, Fleagle briefly surveys behaviour, ecology, morphology and relationships to the level of the genus; the fossil chapters, inevitably, lean more to morphology, though ecology is not ignored. Intervening between the living and fossil sections is a chapter entitled "Primate Adaptation", an interesting miscellany running from body-size effects to the locomotor correlates of ecology. A classification to genus level is given in the first chapter, but neophytes might have benefited from a fourth introductory chapter with an overview of primate systematics and diversity.

One of the most attractive aspects of the book is the way in which extinct primates are presented not simply as teeth and bones but as living, behaving creatures whose lives as a whole we can hope to interpret. This emphasis is complemented well by the illustrations, the preparation of which must have cost the author - let alone his talented artists - at least as much effort as the writing of the text. Several of them show reconstructions of extinct forms disporting themselves in naturalistic, if idyllic, settings; and even the skeletons are caught in the act of behaving.

The occasional error has crept in (Allocebus is not the same size as Microcebus; lemurids and cheirogaleids - as the illustrations show - do not have three incisors), but these are commendably few for such a wide-ranging work. One caveat, though: it is nice to see body weights quoted for extinct primates, but because most are perforce extrapolated from dental dimensions the confidence with which they are presented may be a trifle excessive.

Whereas Fleagle's book fills a longstanding need for a comprehensive and up-to-date introductory text in its field, Human Biology is the third edition of an old favourite first published in 1964. Commendably, the authors have resisted the dismal trend towards simplification that has afflicted introductions to physical anthropology over the past couple of decades; for this reason - as well as, perhaps, the price - the book may, alas, prove in practice more welcome to those preparing comprehensive courses in this eclectic field than to those taking them.

As ever, authoritativeness is assured by the division of responsibility for the four sections (roughly, the human evolution, variation, growth, and adaptability of the subtitle) among four specialists. This new edition is dedicated to the memory of the two of the original four authors (J.S. Weiner and Nigel Barnicot) who have, sadly, died since the last edition appeared. Their original co-authors, as well as their successors, David Pilbeam and Paul Baker, have produced new or revised texts that are informative and thoughtful, and are fully worthy of that memory.

Ian Tattersall is Curator in the Department of Anthropology, American Museum of Natural History, New York, New York 10024, USA.

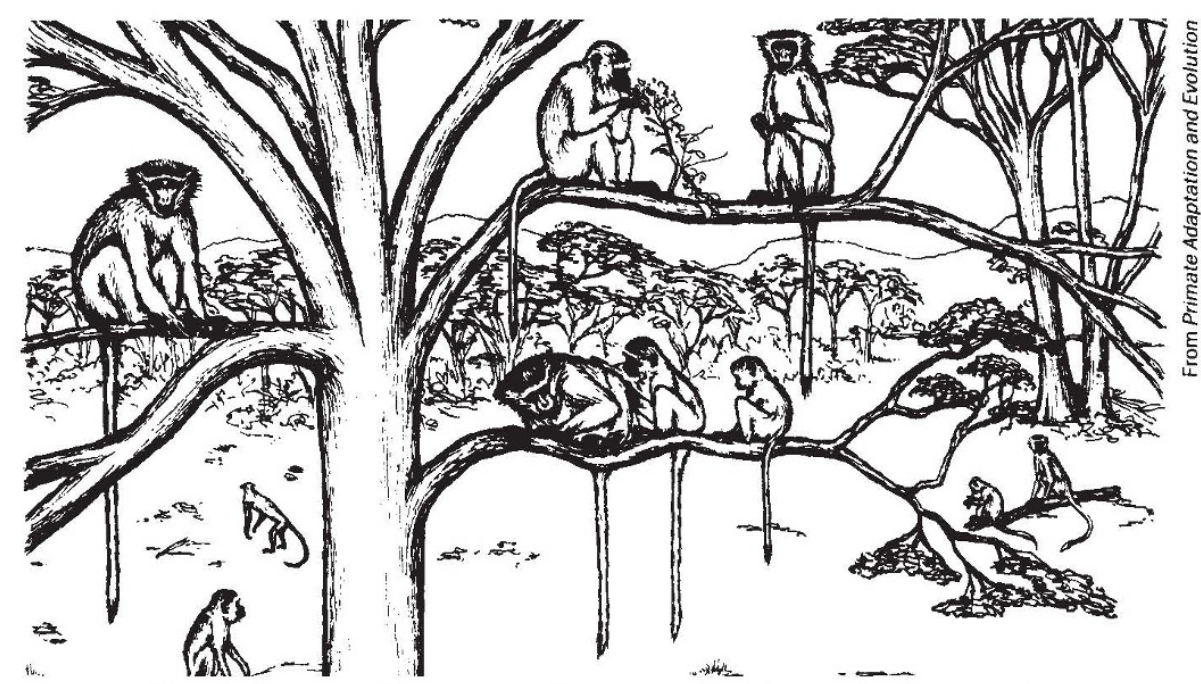

Thereby hangs a tail - a troop of vervet monkeys in woodland savannah. 